Provided for non-commercial research and education use. Not for reproduction, distribution or commercial use.

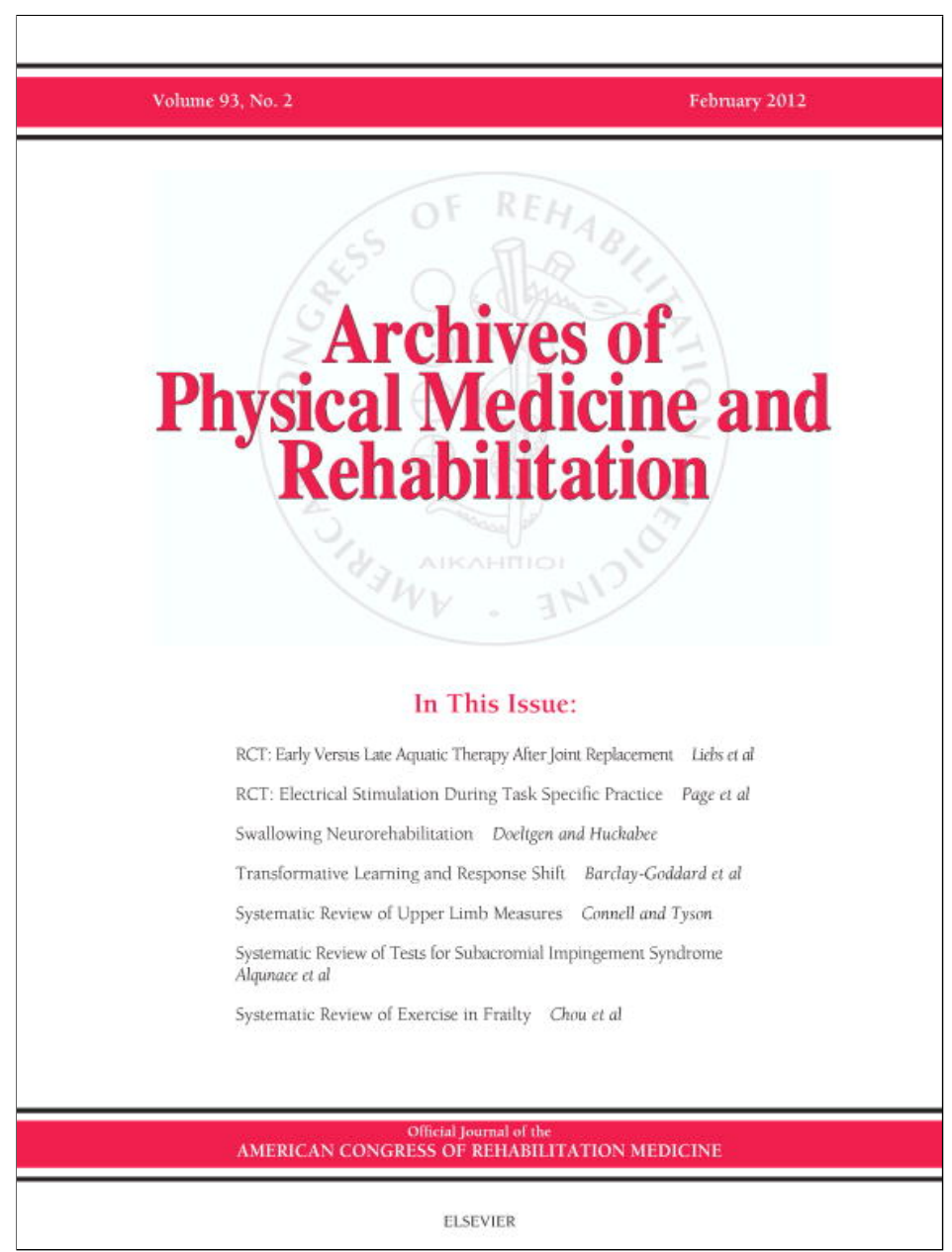

This article appeared in a journal published by Elsevier. The attached copy is furnished to the author for internal non-commercial research and education use, including for instruction at the authors institution and sharing with colleagues.

Other uses, including reproduction and distribution, or selling or licensing copies, or posting to personal, institutional or third party websites are prohibited.

In most cases authors are permitted to post their version of the article (e.g. in Word or Tex form) to their personal website or institutional repository. Authors requiring further information regarding Elsevier's archiving and manuscript policies are encouraged to visit:

http://www.elsevier.com/copyright 


\title{
Role of Fear of Movement in Cancer Survivors Participating in a Rehabilitation Program: A Longitudinal Cohort Study
}

\author{
Miranda J. Velthuis, PhD, Petra H. Peeters, PhD, Brigitte C. Gijsen, MSc, Jan-Paul van den Berg, MD, \\ Ria A. Koppejan-Rensenbrink, MSc, Johan W. Vlaeyen, PhD, Anne M. May, PhD
}

ABSTRACT. Velthuis MJ, Peeters PH, Gijsen BC, van den Berg JP, Koppejan-Rensenbrink RA, Vlaeyen JW, May AM. Role of fear of movement in cancer survivors participating in a rehabilitation program: a longitudinal cohort study. Arch Phys Med Rehabil 2012;93:332-8.

Objective: To study the relationship between fear of movement and perceived global health status and the role of rehabilitation with graded activity in cancer survivors.

Design: Longitudinal cohort study.

Setting: Rehabilitation centers.

Participants: Cancer survivors $(\mathrm{N}=1236)$.

Intervention: Twelve-week graded activity rehabilitation program.

Main Outcome Measures: Fear of movement (Modified Tampa Scale for Kinesiophobia-Fatigue), fatigue (Functional Assessment of Cancer Therapy-Fatigue), and perceived global health status (European Organisation Research and Treatment of Cancer Quality of Life Questionnaire C30) were measured at baseline and after rehabilitation. We performed multiple linear regression analyses to examine the association between fear of movement and perceived global health status at baseline. Differences between baseline and postintervention scores were assessed with a paired $t$ test and effect sizes (ESs). Hierarchical multiple regression analyses were used to investigate whether changes in fear of movement were associated with perceived global health status.

Results: Fear of movement was associated with perceived global health status prior to rehabilitation $(P=.001)$. Only participants with high scores on baseline fear of movement showed a considerable decrease in fear of movement after rehabilitation $(\mathrm{ES}=-.69 ; 95 \%$ confidence interval $[\mathrm{CI}],-.80$ to $-.57)$; the reduction was largest for fears because of a somatic focus $(\mathrm{ES}=-.57 ; 95 \% \mathrm{CI},-.68$ to -.45$)$. Changes in fear of movement because of a somatic focus were related to perceived global health status postintervention $(P=.001)$.

Conclusions: Fear of movement is associated with the perceived global health status of cancer survivors. Fear of move-

From the Comprehensive Cancer Center the Netherlands, Utrecht, (Velthuis, Gijsen, Koppejan-Rensenbrink), University Medical Center Utrecht, Utrecht, Julius Center for Health Sciences and Primary Care, Utrecht (Velthuis, Peeters, May), Department of Clinical Psychological Science, Meander Medical Center, Amersfoort (van den Berg); Maastricht University, Maastricht, the Netherlands; and Department of Clinical Psychological Science (Vlaeyen); Belgium Research Center of Health Psychology, University of Leuven, Leuven, Belgium (Vlaeyen).

Supported by The National Fund for Scientific Research (FWO) Odysseus grant of the Science Foundation of Flanders, Belgium.

No commercial party having a direct financial interest in the results of the research supporting this article has or will confer a benefit on the authors or on any organization with which the authors are associated.

Correspondence to Miranda J. Velthuis, PhD, Comprehensive Cancer Center the Netherlands, location Utrecht, PO Box 19079, 3501 DB Utrecht, The Netherlands, e-mail: mvelthuis@ikmn.nl. Reprints will not be available from the author.

0003-9993/12/9302-00223\$36.00/0

doi:10.1016/j.apmr.2011.08.014 ment decreases after rehabilitation with graded activity in high scorers on baseline fear of movement.

Key Words: Exercise; Neoplasms; Quality of life; Rehabilitation.

(C) 2012 by the American Congress of Rehabilitation Medicine

$\mathbf{U}$ P TO $60 \%$ TO $96 \%$ of the cancer patients report high levels of fatigue during or after cancer treatment, which is expected to lead to a decreased quality of life. ${ }^{1}$ Fatigue may be caused by the cancer itself and/or its treatment. ${ }^{1}$ Several studies-most in breast cancer survivors - show that physical exercise after cancer treatment might lead to a reduction in fatigue and an improvement in quality of life. ${ }^{2,3}$ Of the patients who report fatigue during cancer treatment, up to $30 \%$ continue to experience fatigue years after the end of treatment. ${ }^{1}$ In these patients several factors might be responsible for the persistence of complaints, such as a disruption of activity and an inadequate adjustment to life's goals, while facing cancer and its treatment. ${ }^{4}$ After cancer treatment and a prolonged period of rest during treatment, cancer survivors may perceive activity levels - that were previously well tolerated-as excessive and this may cause fatigue. If the response is to further limit physical activities, instead of gradually increasing them, fatigue may paradoxically persist and also lead to a reduced quality of life. ${ }^{5}$

Previously, in patients without cancer who have symptoms of chronic pain and chronic fatigue, this cognitive behavioral model of fear of movement (kinesiophobia), including the mechanisms as explained above, has been described. ${ }^{6-8} \mathrm{~Pa}-$ tients reporting fear of movement seem to benefit from rehabilitation based on the principles of behavioral graded activity, during which patients are gradually exposed to feared movements. ${ }^{9-11}$ We hypothesize, that the same mechanism of fear of movement explains persistence of complaints of fatigue, at

List of Abbreviations

$\begin{array}{ll}\begin{array}{l}\text { CI } \\ \text { EORTC-QLO-C30 }\end{array} & \begin{array}{c}\text { confidence interval } \\ \text { European Organisation Research and } \\ \text { Treatment of Cancer Quality of } \\ \text { Life Questionnaire C30 } \\ \text { effect size } \\ \text { ES }\end{array} \\ \begin{array}{l}\text { Functional Assessment of Cancer } \\ \text { Therapy-Fatigue } \\ \text { TSK-F }\end{array} & \begin{array}{l}\text { Modified Tampa Scale for } \\ \text { Kinesiophobia-Fatigue } \\ \text { Modified Tampa Scale for } \\ \text { KSK-F AA }\end{array} \\ & \begin{array}{l}\text { Kinesiophobia-Fatigue activity } \\ \text { avoidance }\end{array} \\ \text { TSK-F SF } & \text { Kinesiophobia-Fatigue somatic } \\ \text { focus }\end{array}$


least in part of the cancer survivors. Quality of life and fatigue complaints improved in cancer survivors after rehabilitation, including graded activity. ${ }^{12}$ The aim of the current study is to examine the relationship between fear of movement and perceived global health status in cancer survivors. Furthermore, we will test whether fear of movement and symptoms of fatigue are reduced and perceived global health status is improved after rehabilitation, including graded activity. Finally, we will test whether a decreased fear of movement is associated with a positive change in perceived global health status during the intervention.

\section{METHODS}

\section{Study Participants}

Between 1996 and 2005, cancer survivors (varying in age, sex, type of cancer, and activity level) were referred for rehabilitation by medical specialists and general practitioners, who were familiar with the rehabilitation program that was offered in 4 Comprehensive Cancer Center regions in the Netherlands. Cancer survivors were eligible for rehabilitation if (1) at least 2 months ago, they had finished their last cancer-related treatment (except hormone therapy), (2) they were 18 years or older, (3) the estimated life expectancy was over 1 year and patients were treated with curative intent, and (4) they were judged to be able to participate in a group rehabilitation program.

\section{Group Rehabilitation Program}

A detailed description of the rehabilitation program has been previously published. ${ }^{12}$ The 12 -week program, consisting of physical training and psychoeducation, aimed to enhance quality of life and recovery in cancer survivors. The program was offered to groups of 12 to 16 patients, varying in age, sex, type of cancer, and activity level.

Physical training was offered twice a week, and consisted of endurance and strength training $(2 \times 1 \mathrm{~h})$ and group sports $(1 \times$ 1h) and was based on the principles of graded activity. ${ }^{13}$ This means that the training intensity levels increase gradually, based on incremental rates determined prior to start, a so-called time contingent approach. ${ }^{13}$ Both the endurance and strength training and the group sports were supervised by a physical activity expert, that is, a physical therapist.

The aim of the psychoeducational sessions (seven 2-h sessions) was to improve the knowledge about cancer-related subjects and to stimulate sharing experiences on cancer-related subjects, such as nutrition, lymph oedema, and returning to work. Experts in different cancer-related areas, such as a medical specialist, a dermatologist, or a nutritionist, chaired these sessions.

\section{Measurements}

Patients completed questionnaires at baseline and after 12 weeks (end of the program) measuring the following constructs.

Fear of movement. Fear of movement is measured with the Modified Tampa Scale for Kinesiophobia-Fatigue (TSK-F), which is a questionnaire including 11-items that are scored on a 4-point scale (strongly disagree: 1 to strongly agree: 4). Total scores range from 11 to 44 . The 2-factor model has been shown to have reasonable psychometric properties. ${ }^{14,15}$ The 2 subscales are somatic focus (TSK-F SF) and activity avoidance (TSK-F AA). The somatic focus subscale (5 items) taps into a belief that fatigue is associated with serious underlying medical problems. The subscale activity avoidance (6 items) measures the belief that activity may result in increased fatigue and hence should be avoided. ${ }^{16,17}$ Based on the median score of the TSK-F total, we divided our study sample in high and low scorers based on fear of movement.

Fatigue. Fatigue is measured using the validated questionnaire Functional Assessment of Cancer Therapy-Fatigue (FACT-F). ${ }^{18}$ The FACT-F is part of the Functional Assessment of Cancer Therapy-General, which assesses multiple fatigue characteristics and their impact on function. The FACT-F subscale consists of 13 items and gives a combined score between 0 and 52. Higher scores indicate less fatigue.

Global health status. Perceived global health status is assessed using the subscale of the European Organisation Research and Treatment of Cancer Quality of Life Questionnaire C30 (EORTC-QLQ-C30) (version 2), a reliable and valid measure of quality of life in cancer patients. ${ }^{19}$ Global health status is scored on a scale ranging from very poor (1) to excellent (7). Scores range from 0 to 100 , with a higher scores representing better global health status.

Sociodemographic and medical data. At baseline, age (in years), sex, cancer type, cancer treatment (chemotherapy, radiotherapy), and time since diagnosis (in years) are obtained by self-report.

\section{Statistical Analyses}

Descriptive statistics were used to describe the study population and instrument scores at baseline and at the end of the program. Missing values were replaced by imputed values estimated by an expectation maximization analysis. ${ }^{20}$ Imputed values were used for further analyses.

To evaluate the association of fear of movement with perceived global health status, we performed multiple linear regression analyses. Separate as well as combined analyses were conducted to assess the association of perceived global health status and the 2 domains of fear of movement, activity avoidance, and somatic focus. We investigated the potential confounding effect of fatigue, age, sex, cancer type, and time between diagnosis and start of the program.

Differences between baseline and postintervention scores were assessed with a paired $t$ test, an analysis of variance corrected for baseline, and effect sizes (ESs). ESs less than -0.2 were indicated as no change, ESs of -0.2 to -0.5 as small change, ESs of -0.5 to -0.8 as moderate change, and ESs of -0.8 or higher as considerable change. ${ }^{21}$

To investigate whether changes in fear of movement and fatigue during the intervention were associated with perceived change in global health status, we performed hierarchical multiple regression analyses with perceived change in global health status as the dependent variable. In the first step, perceived global health status at baseline is entered to control for preintervention levels. In the second step, fear of movement, somatic focus and activity avoidance, and fatigue at baseline are entered; in the third step, fear of movement, somatic focus and activity avoidance, and fatigue postintervention are entered into the model. As an acceptable level of significance (2-sided), a $P$ value of less than .05 was taken. These analyses were performed for the full population, and separately for cancer survivors with high and low scores for fear of movement.

We performed separate analyses for a homogeneous sample of patients with breast cancer who finished their treatment less than 2 years ago.

Imputation of missings and statistical analyses were performed by using SPSS for Windows, release 17.0. ${ }^{\mathrm{a}} \mathrm{ESs}$ were calculated using the ES calculator (http://davidmlane.com/ hyperstat/effect_size.html). 


\section{RESULTS}

\section{Study Participants}

A total of 1236 cancer survivors participated in the rehabilitation program between 1996 and 2005. The characteristics of the study population are listed in table 1 . The mean age \pm SD of the participants is $50 \pm 9.6$. Seventy-three percent of the participants were women. About $50 \%$ of the participants were diagnosed with cancer 1 to 3 years prior to rehabilitation. Fifty percent had breast cancer. Eighty-seven percent completed the program $(n=1078)$ and $1 \%$ dropped out $(n=9)$ for several reasons, for example cancer recurrence and personal reasons. For 149 (12\%) participants, it was unknown if they finished the program.

Additionally, we described the baseline characteristics for 3 subgroups: patients less than a half year within cancer diagnosis, patients between a half year and 2 years after diagnosis, and patients more than 2 years after cancer diagnosis. We only found a significant difference in fear of movement for the total score between participants who have been diagnosed less than a half a year within cancer diagnosis and patients more than 2 years after cancer diagnosis $(P=.018)$. For other variables, we found significant differences between subgroups for chemotherapy (yes/no) $(P=.001)$, fatigue $(P=.002)$ and global health status $(P=.029)$.

\section{Relation Fear of Movement With Global Health Status Prior to Rehabilitation (t0)}

Both activity avoidance and fears due to a somatic focus were associated with perceived global health status prior to rehabilitation (table 2). A decrease of 1 unit in activity avoidance (TSK-F AA) was related to an increase of 1 unit in

Table 1: Participants' Characteristics at Baseline (t0)

\begin{tabular}{|c|c|c|c|c|}
\hline \multirow[b]{4}{*}{ Participants' Characteristics } & \multirow[b]{4}{*}{ Total } & \multicolumn{3}{|c|}{ Time Between Diagnosis and Program Start } \\
\hline & & $\leq 0.5 y$ & $0.5-2 y$ & $\geq 2 y$ \\
\hline & & $112(100)$ & $622(100)$ & $278(100)$ \\
\hline & & $0(0)$ & $0(0)$ & $0(100)$ \\
\hline Age at start (y) & $1055(85)$ & $111(99)$ & $620(99)$ & $278(100)$ \\
\hline Missing & $181(15)$ & $1(1)$ & $2(1)$ & $0(100)$ \\
\hline Mean $\pm S D$ & $50 \pm 9.6$ & $49 \pm 9.4$ & $50 \pm 9.5$ & $51 \pm 9.7$ \\
\hline Sex & $1236(100)$ & $112(100)$ & $622(100)$ & $278(100)$ \\
\hline Men & $197(16)$ & $20(18)$ & $101(16)$ & $51(18)$ \\
\hline Women & $898(73)$ & $92(82)$ & $521(84)$ & $226(81)$ \\
\hline Missing & $141(11)$ & $0(0)$ & $0(0)$ & $1(0.5)$ \\
\hline Cancer diagnosis & $1236(100)$ & $112(100)$ & $622(100)$ & $278(100)$ \\
\hline Breast & $615(50)$ & $71(64)$ & $377(61)$ & $146(53)$ \\
\hline Blood/bone marrow/lymphoma & $133(11)$ & $14(13)$ & $59(10)$ & $51(18)$ \\
\hline Digestive tract & $77(6)$ & $10(9)$ & $45(7)$ & $18(7)$ \\
\hline Woman genital tract & $72(6)$ & $3(3)$ & $45(7)$ & $21(8)$ \\
\hline Lower airway & $53(4)$ & $3(3)$ & $40(6)$ & $6(2)$ \\
\hline Other & $89(7)$ & $8(7)$ & $43(7)$ & $30(11)$ \\
\hline Missing & $197(16)$ & $3(3)$ & $13(2)$ & $6(2)$ \\
\hline \multicolumn{5}{|l|}{ Cancer treatment } \\
\hline Chemotherapy & $1236(100)$ & $112(100)$ & $622(100)$ & $278(100)$ \\
\hline Yes & $647(52)$ & $70(73)$ & $395(64)$ & $146(53)$ \\
\hline No & $353(29)$ & $39(35)$ & $178(29)$ & $108(39)$ \\
\hline Missing & $236(19)$ & $3(3)$ & $49(8)$ & $24(9)$ \\
\hline Radiotherapy & $1236(100)$ & $112(100)$ & $622(100)$ & $278(100)$ \\
\hline Yes & $566(46)$ & $59(53)$ & $331(53)$ & $148(53)$ \\
\hline No & $434(35)$ & $50(45)$ & $242(39)$ & $106(38)$ \\
\hline Missing & $236(19)$ & $3(3)$ & $49(8)$ & $24(9)$ \\
\hline \multicolumn{5}{|l|}{ Fear of movement (TSK-F) } \\
\hline Total & $947(77)$ & $89(79)$ & $467(75)$ & $212(76)$ \\
\hline Missing & $289(23)$ & $23(21)$ & $155(25)$ & $66(24)$ \\
\hline Mean \pm SD & $23 \pm 5.8$ & $23 \pm 6.3$ & $23 \pm 5.7$ & $24 \pm 6.0$ \\
\hline Activity avoidance & $988(80)$ & $97(87)$ & $490(79)$ & $217(78)$ \\
\hline Missing & $248(20)$ & $15(13)$ & $132(21)$ & $61(22)$ \\
\hline Mean \pm SD & $12 \pm 3.4$ & $12 \pm 3.5$ & $12 \pm 3.3$ & $13 \pm 3.5$ \\
\hline Somatic focus & $985(80)$ & $89(79)$ & $488(78)$ & $222(80)$ \\
\hline Missing & $251(20)$ & $23(21)$ & $134(22)$ & $56(20)$ \\
\hline Mean $\pm S D$ & $11 \pm 3.5$ & $11 \pm 3.6$ & $11 \pm 3.4$ & $11 \pm 3.5$ \\
\hline Fatigue (FACT-F) & $999(81)$ & $84(75)$ & $496(80)$ & $214(77)$ \\
\hline Missing & $240(19)$ & $28(25)$ & $126(20)$ & $64(23)$ \\
\hline Mean \pm SD & $21 \pm 9.8$ & $20 \pm 9.1$ & $17 \pm 8.5$ & $23 \pm 9.8$ \\
\hline Global health status (EORTC-QLQ-C30) & $1192(96)$ & $111(99)$ & $617(99)$ & $271(97)$ \\
\hline Missing & $44(4)$ & $1(1)$ & $5(1)$ & $7(3)$ \\
\hline Mean \pm SD & $61 \pm 17.2$ & $59 \pm 18.8$ & $62 \pm 16.7$ & $60 \pm 17.9$ \\
\hline
\end{tabular}

NOTE. Values are $\mathrm{n}(\%)$ or as otherwise indicated. 
Table 2: Association Between Fear of Movement and Global Health Status Prior to Rehabilitation (t0)

\begin{tabular}{|c|c|c|c|c|c|c|c|c|c|}
\hline \multirow[b]{3}{*}{ Predictors } & & & & \multicolumn{5}{|c|}{ Global Health Status (t0) } & \\
\hline & \multicolumn{3}{|c|}{ Model 1} & \multicolumn{3}{|c|}{ Model 2} & \multicolumn{3}{|c|}{ Model 3} \\
\hline & $\beta$ & $95 \% \mathrm{Cl}$ & $P$ & $\beta$ & $95 \% \mathrm{Cl}$ & $P$ & $\beta$ & $95 \% \mathrm{Cl}$ & $P$ \\
\hline \multicolumn{10}{|l|}{ Total $(\mathrm{N}=1236)$} \\
\hline $\begin{array}{l}\text { A. Fear of movement activity } \\
\text { avoidance (t0) }\end{array}$ & -1.075 & -1.359 to -0.792 & .001 & -0.594 & -0.836 to -0.352 & .001 & -0.591 & -0.835 to -0.347 & .001 \\
\hline $\begin{array}{l}\text { B. Fear of movement } \\
\text { somatic focus (t0) }\end{array}$ & -1.512 & -1.777 to -1.247 & .001 & -0.920 & -1.066 to -0.597 & .001 & -0.817 & -1.054 to -0.581 & .001 \\
\hline $\begin{array}{l}\text { C. Fear of movement activity } \\
\text { avoidance (t0) }\end{array}$ & -0.529 & -0.829 to -0.229 & .001 & -0.322 & -0.580 to -0.065 & .014 & -0.325 & -0.585 to -0.065 & .014 \\
\hline $\begin{array}{l}\text { Fear of movement somatic } \\
\text { focus (t0) }\end{array}$ & -1.309 & -1.597 to -1.022 & .001 & -0.713 & -0.966 to -0.461 & .001 & -0.699 & -0.953 to -0.445 & .001 \\
\hline $\begin{array}{l}\text { Patients within } 2 y \text { after } \\
\text { finishing breast cancer } \\
\text { treatment }(n=518)\end{array}$ & & & & & & & & & \\
\hline $\begin{array}{l}\text { D. Fear of movement activity } \\
\text { avoidance (t0) }\end{array}$ & -1.040 & -1.481 to -0.599 & .001 & -0.542 & -0.916 to -0.168 & .005 & -0.531 & -0.905 to -0.157 & .005 \\
\hline $\begin{array}{l}\text { E. Fear of movement } \\
\text { somatic focus (t0) }\end{array}$ & -1.473 & -1.909 to -1.037 & .001 & -0.749 & -1.132 to -0.367 & .001 & -0.737 & -1.121 to -0.353 & .001 \\
\hline $\begin{array}{l}\text { F. Fear of movement activity } \\
\text { avoidance (t0) }\end{array}$ & -0.537 & -1.008 to -0.066 & .025 & -0.311 & -0.712 to 0.090 & .129 & -0.304 & -0.705 to 0.098 & .138 \\
\hline $\begin{array}{l}\text { Fear of movement somatic } \\
\text { focus (t0) }\end{array}$ & -1.253 & -1.728 to -0.778 & .001 & -0.628 & -1.014 to -0.216 & .003 & -0.618 & -1.032 to -0.203 & .004 \\
\hline
\end{tabular}

NOTE. Model 1: crude model; Model 2: model 1 adjusted for fatigue (t0); Model 3: model 1 adjusted for fatigue (t0) and additional medical and sociodemographic variables.

perceived global health status (EORTC-QLQ-C30), while a decrease of 1 unit in fear due to a somatic focus (TSK-F SF) resulted in an improvement of perceived global health status (EORTC-QLQ-C30) of 1 and a half units. After correcting for baseline fatigue and medical and sociodemographic variables, the association of both activity avoidance $(P=0.001)$ and fears due to a somatic focus $(P=0.001)$ with perceived global health status was still significant.

Statistical analysis in a homogenous group of patients diagnosed with breast cancer, who finished their treatment less than 2 years ago, show comparable results.

\section{Effects of Rehabilitation on Fear of Movement, Fatigue, and Global Health Status}

Mean values \pm SD for fear of movement, fatigue, and perceived global health status at baseline and after rehabilitation as well as mean differences and ESs are shown in table 3.

For the total study population, we found no change in fear of movement after rehabilitation $(\mathrm{ES}=-.17 ; 95 \%$ confidence interval $[\mathrm{CI}],-.25$ to -.09$)$. However, a considerable decrease in fear of movement in participants with high scores on baseline fear of movement $(\mathrm{ES}=-.69 ; 95 \% \mathrm{CI},-.80$ to -.57$)$ was found. Fears in the domain of somatic focus decreased more after rehabilitation than activity avoidance. In the total population, activity avoidance did not change after rehabilitation $(\mathrm{ES}=-.06 ; 95 \% \mathrm{CI},-.14$ to -.02$)$, while fears due to a somatic focus showed a small decrease $(E S=-.24 ; 95 \% \mathrm{CI}$, -.31 to -.16$)$. In participants with high scores on baseline fear of movement, activity avoidance showed a small decrease $(\mathrm{ES}=-.33 ; 95 \% \mathrm{CI},-.44$ to -.21$)$, while fears due to a somatic focus decreased moderately after rehabilitation $(\mathrm{ES}=-.57 ; 95 \% \mathrm{CI},-.68$ to -.45$)$.

We found a small decrease of fatigue $(E S=-.43 ; 95 \% \mathrm{CI}$, -.50 to -.35$)$ after rehabilitation. This decrease did not differ between high scorers and low scorers on baseline fear of movement (see table 3).
Perceived global health status scores showed a small increase after rehabilitation ( $\mathrm{ES}=.44 ; 95 \% \mathrm{CI}, .36-.52)$. This mean improvement was higher in those with high scores on baseline fear of movement (see table 3).

Change scores corrected for baseline values show significant improvements in fear of movement, fatigue, and global health status, for high and low scorers of fear of movement.

\section{Associations of Changes in Fear of Movement and Change in Global Health Status}

Changes in fears due to a somatic focus were related to the perceived global health status after rehabilitation, and also after correcting for baseline values of perceived global health status, activity avoidance, somatic focus, and fatigue at follow-up $(P=.001)$ (table 4). Changes in activity avoidance were not related to perceived global health status after rehabilitation $(P=.639)$.

Comparable results are found in high scorers and low scorers on baseline fear of movement and in patients within 2 years after finishing their breast cancer treatment.

\section{DISCUSSION}

We investigated the relation between fear of movement and perceived global health status in cancer survivors. We studied whether fear of movement was reduced and symptoms of fatigue and perceived global health status were improved after rehabilitation with graded activity. Finally, we assessed whether a decreased fear of movement is associated with a positive change in perceived global health status.

In cancer survivors prior to rehabilitation, both activity avoidance and fears due to a somatic focus were negatively associated with perceived global health status. We found no change in fear of movement and small improvements in complaints of fatigue and perceived global health status after rehabilitation. However, the results of participants with high base- 
Table 3: Mean Scores and Mean Differences on Fear of Movement, Fatigue, and Global Health Status (t0 and $t 1$ )

\begin{tabular}{|c|c|c|c|c|c|}
\hline Variables & $\begin{array}{c}\text { Mean } \\
\text { Baseline } \pm \text { SD }\end{array}$ & $\begin{array}{c}\text { Mean } \\
\text { Posttest } \pm \text { SD }\end{array}$ & $\begin{array}{l}\text { Mean Difference } \\
(95 \% \mathrm{Cl})^{*}\end{array}$ & ES $(95 \% \mathrm{CI})^{*}$ & $\begin{array}{l}\text { Change Corrected for } \\
\text { Baseline }^{\dagger}(95 \% \mathrm{Cl})\end{array}$ \\
\hline \multicolumn{6}{|l|}{ Fear of movement (TSK-F) } \\
\hline Total (range, 11-44) (N=1236) & $23.2 \pm 5.8$ & $22.2 \pm 5.8$ & $-1.0(-1.3$ to -0.7$)$ & $-0.17(-0.25$ to -0.09$)$ & 0.57 (0.52 to 0.62$)$ \\
\hline$\%$ missing & 23 & 31 & & & \\
\hline High scorers fear of movement $(n=613)^{\S}$ & $28.0 \pm 3.4$ & $24.9 \pm 5.4$ & $-3.0(-3.5$ to -2.7$)$ & $-0.69^{\ddagger}(-0.80$ to -0.57$)$ & $0.61(0.50$ to 0.73$)$ \\
\hline Low scorers fear of movement $(n=623)^{\|}$ & $18.5 \pm 3.2$ & $19.5 \pm 4.8$ & $1.0(0.7$ to 1.4$)$ & $0.25^{\ddagger}(0.13$ to 0.36$)$ & $0.53(0.41$ to 0.64$)$ \\
\hline Activity avoidance (range, 6-24) $(\mathrm{N}=1236)$ & $12.4 \pm 3.3$ & $12.2 \pm 3.5$ & $-0.2(-0.4$ to -0.03$)$ & $-0.06(-0.14$ to -0.02$)$ & $0.50(0.44$ to 0.55$)$ \\
\hline$\%$ missing & 20 & 29 & & & \\
\hline High scorers fear of movement $(n=613)^{\S}$ & $14.4 \pm 2.8$ & $13.4 \pm 3.3$ & $-1.0(-1.2$ to -0.7$)$ & $-0.33^{\ddagger}(-0.44$ to -0.21$)$ & $0.50(0.42$ to 0.59$)$ \\
\hline Low scorers fear of movement $(n=623)^{\|}$ & $10.5 \pm 2.6$ & $11.0 \pm 3.2$ & $0.5(0.3$ to 0.8$)$ & $0.17(0.06$ to 0.28$)$ & $0.36(0.27$ to 0.45$)$ \\
\hline Somatic focus (range, $5-20)(N=1236)$ & $10.8 \pm 3.5$ & $10.0 \pm 3.3$ & $-0.8(-1.0$ to -0.6$)$ & $-0.24^{\ddagger}(-0.31$ to -0.16$)$ & $0.51(0.46$ to 0.55$)$ \\
\hline$\%$ missing & 20 & 30 & & & \\
\hline High scorers fear of movement $(n=613)^{\S}$ & $13.0 \pm 2.8$ & $11.3 \pm 3.2$ & $-1.6(-1.9$ to -1.4$)$ & $-0.57^{\ddagger}(-0.68$ to -0.45$)$ & $0.46(0.38$ to 0.54$)$ \\
\hline Low scorers fear of movement $(n=623)^{\|}$ & $8.6 \pm 2.6$ & $8.7 \pm 2.9$ & $0.04(-0.2$ to 0.3$)$ & $0.04(-0.07$ to 0.15$)$ & $0.42(0.35$ to 0.50$)$ \\
\hline Fatigue (FACT-F) (range, $0-52)(\mathrm{N}=1236)$ & $21.8 \pm 9.7$ & $17.8 \pm 9.1$ & $-3.9(-4.4$ to -3.5$)$ & $-0.43^{ \pm}(-0.50$ to -0.35$)$ & $0.60(0.56$ to 0.64$)$ \\
\hline$\%$ missing & 19 & 30 & & & \\
\hline High scorers fear of movement $(n=613)^{\S}$ & $23.9 \pm 9.3$ & $19.7 \pm 9.1$ & $-4.2(-4.8$ to -3.5$)$ & $-0.46^{\ddagger}(-0.57$ to -0.34$)$ & 0.62 (0.56 to 0.68$)$ \\
\hline Low scorers fear of movement $(n=623)^{\|}$ & $19.7 \pm 9.6$ & $16.0 \pm 8.8$ & $-3.7(-4.3$ to -3.0$)$ & $-0.40^{\ddagger}(-0.51$ to -0.29$)$ & $0.55(0.50$ to 0.61$)$ \\
\hline \multicolumn{6}{|l|}{ Global health status (EORTC-QoL-C30) } \\
\hline (range, $0-100)(n=1236)$ & $61.2 \pm 17.3$ & $68.8 \pm 17.0$ & 7.6 (6.6 to 8.5$)$ & $0.44^{\ddagger}(0.36$ to 0.52$)$ & $0.46(0.41$ to 0.51$)$ \\
\hline$\%$ missing & 4 & 17 & & & \\
\hline High scorers fear of movement $(n=613)^{\S}$ & $57.0 \pm 16.9$ & $65.6 \pm 17.3$ & $8.6(7.1$ to 10.0$)$ & $0.50^{\ddagger}(0.39$ to 0.62$)$ & $0.45(0.38$ to 0.53$)$ \\
\hline Low scorers fear of movement $(n=623)^{\|}$ & $65.2 \pm 16.7$ & $71.8 \pm 16.1$ & 6.5 (5.2 to 7.9$)$ & $0.40^{\ddagger}(0.29$ to 0.51$)$ & $0.43(0.37$ to 0.50$)$ \\
\hline
\end{tabular}

*Not corrected for baseline.

+Unstandardized coefficients analysis of variane change corrected for baseline.

Imputed data $(\mathrm{N}=1236)$ were used; ${ }^{\ddagger} \mathrm{ES} \geq 0.2 ;{ }^{\S} \geq$ median score $=23, \mathrm{TSK}-\mathrm{F}(\mathrm{t} 0) ; \|<$ median score $=23, \mathrm{TSK}-\mathrm{F}(\mathrm{t} 0)$.

line fear of movement scores showed a considerable decrease in fear of movement, the largest in movement fears due to a somatic focus. Reductions in these fears of movement were related to perceived change in global health status. We found no associations of activity avoidance with change in perceived global health status after rehabilitation.

Fear of movement was negatively associated with perceived global health status. This is in accordance with a previous study. $^{22}$
Although we found small improvements in fatigue and perceived global health status, we found no decrease in fear of movement (1 point on the TSK-F) after rehabilitation. These findings are not fully in accordance with previous studies investigating rehabilitation with graded activity in patients with chronic pain. ${ }^{10,11,23}$ Vonk, ${ }^{10}$ Staal, ${ }^{11}$ and Woods, ${ }^{23}$ and colleagues found improvements in functioning and return to work, as well as improvements on the TSK-F, varying between 2 to 4 points postintervention. These differences in improvements

Table 4: Multiple Hierarchical Regression Analysis Predicting $\Delta$ Global Health Status

\begin{tabular}{|c|c|c|c|c|c|c|c|c|c|}
\hline \multirow[b]{2}{*}{ Predictors } & \multicolumn{3}{|c|}{ Total } & \multicolumn{3}{|c|}{ High Scorers Fear of Movement* } & \multicolumn{3}{|c|}{ Low Scorers Fear of Movement ${ }^{\dagger}$} \\
\hline & $\beta$ & $95 \% \mathrm{Cl}$ & $P$ & $\beta$ & $95 \% \mathrm{Cl}$ & $P$ & $\beta$ & $95 \% \mathrm{Cl}$ & $P$ \\
\hline Total & \multicolumn{3}{|c|}{$N=1236$} & \multicolumn{3}{|c|}{$\mathrm{n}=613$} & \multicolumn{3}{|c|}{$\mathrm{n}=623$} \\
\hline avoidance $(\mathrm{t} 1)$ & -0.060 & -0.310 to 0.190 & 639 & 0.041 & -0.336 to 0.418 & .831 & -0.180 & -0.514 to 0.153 & .289 \\
\hline \multicolumn{10}{|l|}{ Fear of movement, } \\
\hline somatic focus (t1) & -0.590 & -0.864 to -0.317 & .001 & -0.462 & -0.845 to -0.079 & .018 & -0.717 & -1.113 to -0.320 & .001 \\
\hline \multicolumn{10}{|l|}{$\begin{array}{l}\text { Patients within } 2 y \text { after } \\
\text { finishing breast cancer }\end{array}$} \\
\hline treatment & \multicolumn{3}{|c|}{$n=518$} & \multicolumn{3}{|c|}{$n=278$} & \multicolumn{3}{|c|}{$n=240$} \\
\hline $\begin{array}{l}\text { Fear of movement, activity } \\
\text { avoidance (t1) }\end{array}$ & 0.019 & -0.366 to 0.404 & .922 & 0.206 & -0.392 to 0.804 & .498 & -0.295 & -0.802 to 0.211 & .252 \\
\hline $\begin{array}{l}\text { Fear of movement, } \\
\text { somatic focus }(\mathrm{t} 1)\end{array}$ & -0.836 & -1.283 to -0.390 & .001 & -1.159 & -1.815 to 0.503 & .001 & -0.529 & -1.144 to 0.087 & .092 \\
\hline Fatigue $(\mathrm{t} 1)$ & -0.800 & -0.971 to -0.629 & .001 & -0.818 & -1.076 to -0.560 & .001 & -0.736 & -0.965 to -0.506 & .001 \\
\hline
\end{tabular}

NOTE. Unstandardized betas from the last step in the analyses are displayed. In each step, a block of independent variables is entered in the following order. Step 1: global health status (t0); step 2: fear of movement, activity avoidance (t0), fear of movement, somatic focus (t0), fatigue (t0); step 3: fear of movement, activity avoidance (t1), fear of movement, somatic focus (t1), fatigue (t1). Dependent variable: $\Delta$ global health status.

* $\geq$ median score $=23$, TSK-F $(\mathrm{t} 0)$

$\dagger<$ median score $=23$, TSK-F (t0). 
in fear of movement can be explained by the use of different models of the TSK-F: in these studies a 17 -item model ${ }^{10,11,23}$ (range, 17-68) was used, while we used a 11-item model (range, 11-42). ${ }^{14}$ Furthermore, this difference might have been caused by our study population. In previous studies, graded activity was studied in patients with chronic pain or chronic fatigue, persisting for a long time $(>6 \mathrm{mo})$, in which other medical treatment options for their complaints failed. In our study, cancer survivors shortly after they had finished cancer treatment were included. The persistence of fatigue may be caused by cancer (treatment)-related problems or fatigue will not resolve due to fear of movement, with subsequent risk of becoming chronic. This rehabilitation program may be particularly helpful for this latter patient group. Because we identified, not specifically, patients in which other treatment options failed and complaints may persist due to fear of movement, we probably included both groups, which might have led to an underestimation of the effect.

For high and low scores on baseline fear of movement, we found that fears due to a somatic focus decreased more during rehabilitation with graded activity than activity avoidance. A previously conducted randomized trial-comparing graded activity with graded exposure-showed that graded exposure is more effective in reducing avoidance than graded activity. ${ }^{23}$ During graded exposure treatment, participants are gradually exposed to previously avoided activities leading to the elimination of the fear of movement, while during graded activity, the intensity levels of the physical training gradually increase, according to the principles of operant conditioning. Leeuw et $\mathrm{al}^{24}$ suggested that graded exposure might be more effective in patients with high levels of fear of movement, because graded activity may leave too much room for escape and avoidance of feared behaviors. Nijs et $\mathrm{al}^{7}$ confirmed this in their study in patients with chronic fatigue. They found that graded activity might worsen the condition of these patients, but that they may benefit from graded exposure instead.

Reductions in fear of movement due to a somatic focus were related to perceived global health status in our population but not in patients with chronic pain. ${ }^{17,25,26}$ Boersma and Linton ${ }^{25}$ found that activity avoidance had a unique predictive value for pain and disability, while fear due to a somatic focus had no unique predictive value. Geisser, ${ }^{26}$ and Roelofs, ${ }^{17}$ and colleagues also found that activity avoidance was more strongly associated with future behavior than fears due to a somatic focus.

\section{Study Limitations}

Although our findings are promising, especially for high scorers on baseline fear of movement, these results should be interpreted with care. Initially, the lack of a control group made it impossible to determine whether the improvements resulted from rehabilitation or was an effect of the natural course after finishing cancer treatment. Moreover, the better results for the high fearful patients may just have been the effect of the regression to the mean. Second, it was impossible to determine whether changes in fear of movement and perceived global health status were a result of the physical training, the psychoeducation, or the combination. Finally, the reliance on self-reported outcome measures may have introduced bias.

\section{CONCLUSIONS}

\section{Recommendations for Research}

Fear of movement seems to influence perceived global health status of cancer survivors and appears to decrease after rehabilitation with graded activity in cancer survivors with high levels of fear of moment. Specific fear with a somatic focus is associated with less perceived global health status after rehabilitation. Future research should be conducted that might help to identify reference values for fear of movement in cancer survivors. Subsequently, randomized controlled studies should be conducted in cancer survivors with increased fear of movement, to investigate effectiveness of graded activity and graded exposure.

\section{Recommendations for Practice}

Despite the fact that scientific evidence is lacking, we expect that cancer survivors with increased fear of movement might benefit from rehabilitation focused on reducing fear of movement. Cancer survivors without fear of movement seem to benefit less from these programs and can be offered regular exercise programs.

Acknowledgment: We thank Margriet van der Heiden, MSc, for her data management.

\section{References}

1. Lucia A, Earnest C, Perez M. Cancer-related fatigue: can exercise physiology assist oncologists? Lancet Oncol 2003;4:616-25.

2. Cramp F, Daniel J. Exercise for the management of cancer-related fatigue in adults. Cochrane Database Syst Rev. 2008 Apr 16;(2): CD006145

3. Knols R, Aaronson NK, Uebelhart D, Fransen J, Aufdemkampe G. Physical exercise in cancer patients during and after medical treatment: a systematic review of randomized and controlled clinical trials. J Clin Oncol 2005;23:3830-42.

4. Gielissen MF, Verhagen CA, Bleijenberg G. Cognitive behaviour therapy for fatigued cancer survivors: long-term follow-up. Br J Cancer 2007;97:612-8

5. Wessely S, Hotopf M, Sharpe M. Physical mechanisms of fatigue; fatigue and inactivity. In: Chronic fatigue and its syndromes. Oxford: Oxford University Press; 1998. p 55-5.

6. Vlaeyen JW, Kole-Snijders AM, Boeren RG, van Eek H. Fear of movement/(re)injury in chronic low back pain and its relation to behavioral performance. Pain 1995;62:363-72.

7. Nijs J, De Meirleir K, Duquet W. Kinesiophobia in chronic fatigue syndrome: assessment and associations with disability. Arch Phys Med Rehabil 2004;85:1586-92.

8. Silver A, Haeney M, Vijayadurai P, Wilks D, Pattrick M, Main CJ. The role of fear of physical movement and activity in chronic fatigue syndrome. J Psychosom Res 2002;52:485-93.

9. Torenbeek M, Mes CA, van Liere MJ, et al. [Favourable results of a rehabilitation programme with cognitive behavioural therapy and graded physical activity in patients with the chronic-fatigue syndrome] [Dutch]. Ned Tijdschr Geneeskd 2006;150:2088-94.

10. Vonk F, Verhagen AP, Twisk JW, Koke AJ, Luiten MW, Koes BW. Effectiveness of a behaviour graded activity program versus conventional exercise for chronic neck pain patients. Eur J Pain 2009;13:533-41

11. Staal JB, Hlobil H, Koke AJ, Twisk JW, Smid T, van Mechelen W. Graded activity for workers with low back pain: who benefits most and how does it work? Arthritis Rheum 2008;59:642-9.

12. Korstjens I, Mesters I, van der Peet E, Gijsen B, van den Borne B. Quality of life of cancer survivors after physical and psychosocial rehabilitation. Eur J Cancer Prev 2006;15:541-7.

13. Lindstrom I, Ohlund C, Eek C, et al. The effect of graded activity on patients with subacute low back pain: a randomized prospective clinical study with an operant-conditioning behavioral approach. Phys Ther 1992;72:279-90.

14. Roelofs J, Sluiter JK, Frings-Dresen MH, et al. Fear of movement and (re)injury in chronic musculoskeletal pain: evidence for an 
invariant two-factor model of the Tampa Scale for Kinesiophobia across pain diagnoses and Dutch, Swedish, and Canadian samples. Pain 2007;131:181-90.

15. Velthuis MJ, Van den Bussche E, May AM, Gijsen BC, Nijs S, Vlaeyen JW. Fear of movement in cancer survivors: validation of the Modified Tampa Scale of Kinesiophobia-Fatigue. Psychooncology 2011 May 2. [Epub ahead of print].

16. Goubert L, Crombez G, Van Damme S, Vlaeyen JW, Bijttebier P, Roelofs J. Confirmatory factor analysis of the Tampa Scale for Kinesiophobia: invariant two-factor model across low back pain patients and fibromyalgia patients. Clin J Pain 2004;20:103-10.

17. Roelofs J, Goubert L, Peters ML, Vlaeyen JW, Crombez G. The Tampa Scale for Kinesiophobia: further examination of psychometric properties in patients with chronic low back pain and fibromyalgia. Eur J Pain 2004;8:495-502.

18. Yellen SB, Cella DF, Webster K, Blendowski C, Kaplan E. Measuring fatigue and other anemia-related symptoms with the Functional Assessment of Cancer Therapy (FACT) measurement system. J Pain Symptom Manage 1997;13:63-74.

19. Aaronson NK, Ahmedzai S, Bergman B, et al. The European Organization for Research and Treatment of Cancer QLQ-C30: a quality-of-life instrument for use in international clinical trials in oncology. J Natl Cancer Inst 1993;85:365-76.

20. Azen SP, Van Guilder M, Hill MA. Estimation of parameters and missing values under a regression model with non-normally distributed and non-randomly incomplete data. Stat Med 1989;8:217-28.
21. Middel B, Stewart R, Bouma J, van Sonderen E, van den Heuvel WJ. How to validate clinically important change in health-related functional status. Is the magnitude of the effect size consistently related to magnitude of change as indicated by a global question rating? J Eval Clin Pract 2001;7:399-410.

22. van Ittersum M, de Greef M, van Gelder I, Coster J, Brugemann J, van der Schans C. Fear of exercise and health-related quality of life in patients with an implantable cardioverter defibrillator. Int $\mathrm{J}$ Rehabil Res 2003;26:117-22.

23. Woods MP, Asmundson GJ. Evaluating the efficacy of graded in vivo exposure for the treatment of fear in patients with chronic back pain: a randomized controlled clinical trial. Pain 2008;136: 271-80.

24. Leeuw M, Goossens ME, van Breukelen GJ, et al. Exposure in vivo versus operant graded activity in chronic low back pain patients: results of a randomized controlled trial. Pain 2008;138: 192-207.

25. Boersma K, Linton SJ. Expectancy, fear and pain in the prediction of chronic pain and disability: a prospective analysis. Eur J Pain 2006;10:551-7.

26. Geisser ME, Haig AJ, Theisen ME. Activity avoidance and function in persons with chronic back pain. J Occup Rehabil 2000;10: 215-27.

Supplier

a. SPSS Inc, 233 S Wacker Dr, 11th Fl, Chicago, Il 60606. 